\title{
Poly(4-hydroxybutyrate) (P4HB) production in recombinant Escherichia coli: P4HB synthesis is uncoupled with cell growth
}

\author{
Sylvaine Le Meur ${ }^{1,2}$, Manfred Zinn ${ }^{1,3}$, Thomas Egli ${ }^{2,4}$, Linda Thöny-Meyer ${ }^{1}$ and Qun Ren ${ }^{1 *}$
}

\begin{abstract}
Background: Poly(4-hydroxybutyrate) (P4HB), belonging to the family of bacterial polyhydroxyalkanoates (PHAs), is a strong, flexible and absorbable material which has a large variety of medical applications like tissue engineering and drug delivery. For efficient production of P4HB recombinant Escherichia coli has been employed. It was previously found that the P4HB synthesis is co-related with the cell growth. In this study, we aimed to investigate the physiology of P4HB synthesis, and to reduce the total production cost by using cheap and widely available xylose as the growth substrate and sodium 4-hydroxybutyrate ( $\mathrm{Na}-4 \mathrm{HB})$ as the precursor for P4HB synthesis.

Results: Six different $E$. coli strains which are able to utilize xylose as carbon source were compared for their ability to accumulate P4HB. E. coli JM109 was found to be the best strain regarding the specific growth rate and the P4HB content. The effect of growth conditions such as temperature and physiological stage of Na-4HB addition on P4HB synthesis was also studied in E. coli JM109 recombinant in batch culture. Under the tested conditions, a cellular $\mathrm{P} 4 \mathrm{HB}$ content in the range of 58 to $70 \%\left(\mathrm{w} \mathrm{w}^{-1}\right)$ and $\mathrm{P} 4 \mathrm{HB}$ concentrations in the range of 2.76 to $4.33 \mathrm{~g} \mathrm{~L}^{-1}$ were obtained with a conversion yield $\left(\mathrm{Y}_{\mathrm{P} 4 \mathrm{HB} / \mathrm{Na}-4 \mathrm{HB}}\right)$ of $92 \% \mathrm{~W} \mathrm{w}^{-1}$ in single stage batch cultures. Interestingly, three phases were identified during P4HB production: the "growth phase", in which the cells grew exponentially, the "accumulation phase", in which the exponential cell growth stopped while P4HB was accumulated exponentially, and the "stagnation phase", in which the P4HB accumulation stopped and the total biomass remained constant.

Conclusions: P4HB synthesis was found to be separated from the cell growth, i.e. P4HB synthesis mainly took place after the end of the exponential cell growth. High conversion rate and P4HB contents from xylose and precursor were achieved here by simple batch culture, which was only possible previously through fed-batch high cell density cultures with glucose.
\end{abstract}

Keyword: P4HB, Xylose, Bioprocess development, Batch culture

\section{Background}

Natural polyhydroxyalkanoates (PHAs) are synthesized by many microorganisms as carbon and energy storage compounds and deposited as granules in their cytoplasm. PHA accumulation appears when bacterial cells grow under conditions where nutrients other than carbon source, such as nitrogen or phosphorus, are limiting growth. Depending on the carbon substrate supplied, PHAs with different composition are produced. They are classified as short-

\footnotetext{
* Correspondence: qun.ren@empa.ch

'Laboratory for Biomaterials, Swiss Federal Laboratories for Materials Science and Technology (Empa), Lerchenfeldstrasse 5, CH-9014, St. Gallen,

Switzerland

Full list of author information is available at the end of the article
}

chain, medium-chain and long-chain length PHAs according to the number of carbon atoms of the monomeric units [1]. Over a hundred different carboxylic acid monomers were reported to be incorporated into PHAs, resulting in polymers with a wide range of material properties [1]. These natural polymers have attracted particular attention due to their biodegradability and biocompatibility [2-4]. Among them, poly(4-hydroxybutyrate) (P4HB) is a highly interesting polymer for various biomedical applications [5].

P4HB biosynthesis has been studied for about 20 years and it was, and still is, the first and only PHA-based product approved by the FDA as an absorbable suture for clinical application. It is a strong, flexible thermoplastic material that can be processed easily to scaffolds, 
heart valves or cardiovascular tissue supports [5]. The most remarkable property of $\mathrm{P} 4 \mathrm{HB}$ is its very high elasticity and molecular weight, as both benchmark closely to ultra-high molecular weight polyethylene [6]; it can be stretched 10-times its original length before breaking [5]. In addition, P4HB is biocompatible and extremely well tolerated in vivo because biological hydrolysis of P4HB yields $4 \mathrm{HB}$, which is a common metabolite in the human body [7]. When used in vivo, the degradation of P4HB implant takes place via surface erosion and does not lead to a burst release of acid, which is an immense advantage for medical applications [5]. Thus, it is highly desired to obtain $\mathrm{P} 4 \mathrm{HB}$ in large scale at a competitive cost. It was reported that up to $50 \%$ of the total cost of poly(3-hydroxybutyrate) (P3HB) arises from the carbon source [8]. Therefore, to reduce the cost of the carbon source used for large scale $\mathrm{P} 4 \mathrm{HB}$ production, agricultural derived feedstock such as processed hemicelluloses may be employed as a co-substrate to produce the bacterial biomass.

Annually, 60 billion tons of hemicelluloses are produced and remain mostly unused [9]. Hemicellulose is the third most abundant polymer in nature and can be hydrolyzed into simple sugars by either chemical or enzymatic hydrolysis [10]. The dominant building unit of hemicelluloses is xylose. In some plants, xylose polymer (xylan) comprises up to $40 \%$ of the total dry plant material. Xylose can be used as an industrially relevant carbon source for bacterial growth, for example, by Escherichia coli strains [11].

Up to now, several wild-type bacterial strains have been reported to be able to produce $\mathrm{P}(3 \mathrm{HB}-\mathrm{co}-4 \mathrm{HB})$ copolymer: Ralstonia eutropha, Alcaligenes latus, Comamonas acidovorans, Comamonas testosteroni and Hydrogenophaga pseudoflava [12,13]. Saito and coworkers reported the production of $\mathrm{P}(3 \mathrm{HB}-\mathrm{co}-4 \mathrm{HB})$ copolymers by $R$. eutropha using different carbon sources with or without $4 \mathrm{HB}$ as precursor, however, only very low cellular polymer contents were obtained [13]. It was also reported that a maximum of $21 \% \mathrm{w} \mathrm{w} \mathrm{w}^{-1}$ of $\mathrm{P} 4 \mathrm{HB}$ can be achieved by C. acidovorans when using $4 \mathrm{HB}$ or 1,4-butanediol as precursor [13]. Kim and colleagues performed fed-batch experiments with $R$. eutropha supplying in the first step fructose and in the second step only $4 \mathrm{HB}$. They obtained a cell concentration of $33.6 \mathrm{~g} \mathrm{~L}^{-1}$ and a $\mathrm{P}(3 \mathrm{HB}-\mathrm{co}-4 \mathrm{HB})$ copolymer content of $41.7 \% \mathrm{w} \mathrm{w}^{-1}$ with $25 \mathrm{~mol} \% 4 \mathrm{HB}$ [12]. To produce P4HB homopolymers recombinant strains were mainly used.

It has been shown previously that microorganisms that do not produce PHA naturally are ideally suited for the manipulation of the levels of the PHA biosynthetic enzymes and, hence, allow to increase polymer productivity [14]. Wild-type E. coli strains cannot synthesize any type of PHA, including P4HB. By introducing the $\mathrm{P} 4 \mathrm{HB}$ synthesizing genes, recombinant $E$. coli strains are able to produce $\mathrm{P} 4 \mathrm{HB}$ through the newly acquired biosynthetic pathway. It has been reported that the overexpression of PHA synthase (phaC) and $\beta$-ketothiolase (phaA) genes from $R$. eutropha allowed $C$. acidovarans to produce up to $51 \% \mathrm{w} \mathrm{w}^{-1}$ P4HB [15]. By introducing phaC from $R$. eutropha and a 4-hydroxybutyric acid-coenzyme A transferase gene (orfZ) from Clostridium kluyveri, E. coli strain XL1-Blue was able to produce P4HB when $4 \mathrm{HB}$ was supplied as a precursor in the culture medium [16]. A P4HB content of $58.5 \% \mathrm{w} \mathrm{w}^{-1}$ was achieved in $100 \mathrm{~mL}$ shake flasks, however, information on the biomass concentration was not mentioned [16]. Recently, Zhou et al. reported that E. coli JM109 mutant carrying two plasmids reached about $1.9 \mathrm{~g} \mathrm{~L}^{-1} \mathrm{P} 4 \mathrm{HB}$ and $35 \%$ $\left(\mathrm{w} \mathrm{w}^{-1}\right)$ P4HB using LB medium containing glucose in a batch culture [17]. There, LB rich medium was applied and two antibiotics were needed to keep the plasmids, which might be too expensive for large-scale production.

The importance of choosing a suitable E. coli host strain for recombinant culture cultivation was demonstrated by Luli and Strohl [18], who showed that specific growth rate, biomass yield, and acetate formation varied significantly among different strains tested. It has also been reported that among different $E$. coli strains $E$. coli JM109 was the only strain that allowed good production of poly(L-aspartyl-L-phenylalanine) [19]. Up to now, little effort has been made to understand the physiology of P4HB synthesis in E. coli.

In this study, we compared $\mathrm{P} 4 \mathrm{HB}$ production in different $E$. coli recombinants and identified the best $E$. coli strain regarding cell growth and $\mathrm{P} 4 \mathrm{HB}$ accumulation. The effect of growth conditions in batch culture was studied for following parameters: temperature, the carbon source, and $\mathrm{Na}-4 \mathrm{HB}$ concentrations. Furthermore, the best physiological stage at which $\mathrm{Na}-4 \mathrm{HB}$ precursor should be added was investigated. $\mathrm{P} 4 \mathrm{HB}$ productivity of 0.027 $\mathrm{w} \mathrm{w}^{-1} \mathrm{~h}^{-1}$ with excellent conversion yield $\mathrm{Y}_{\mathrm{P} 4 \mathrm{HB} / \mathrm{Na}-4 \mathrm{HB}}$ of $92 \% \mathrm{w} \mathrm{w}^{-1}$ was achieved.

\section{Results}

Comparison of different $E$. coli recombinants for and influence of $4 \mathrm{HB}$ concentrations on P4HB production

Six different $E$. coli strains were transformed with plasmid pKSSE5.3 carrying the necessary genes for P4HB synthesis, namely a PHA synthase gene $(p h a C)$ from $R$. eutropha and a 4-hydroxybutyric acid-coenzyme A transferase gene (orfZ) from C. kluyveri. An initial screening on the performance of the obtained recombinant strains was conducted in shake flasks containing modified E2 medium with xylose as the growth substrate and $\mathrm{Na}-4 \mathrm{HB}$ for $\mathrm{P} 4 \mathrm{HB}$ synthesis. Specific growth rate, maximum optical density $\left(\mathrm{OD}_{600}\right)$ and $\mathrm{P} 4 \mathrm{HB}$ accumulation were measured with time. For comparison, the same experiments were performed with glucose as the growth substrate. The tested $E$. 
coli recombinants exhibited different specific growth rates and accumulated different amounts of P4HB (Figure 1). On both glucose and xylose, the W3110 and BL21(DE3) recombinants displayed a high specific growth rate, but accumulated only negligible amounts of P4HB. Specific growth rates of $\mathrm{DH} 5 \alpha$ and XL1-Blue recombinants were much lower on xylose than on glucose, and the P4HB content in the range of $11 \%$ to $18 \%\left(\mathrm{w} \mathrm{w}^{-1}\right)$ was measured during growth on both sugars. On xylose the best performer for P4HB production was the recombinant JM109, which exhibited a specific growth rate of $0.28 \mathrm{~h}^{-1}$ and accumulated $\mathrm{P} 4 \mathrm{HB}$ up to $19 \%\left(\mathrm{w} \mathrm{w}^{-1}\right)$. E. coli JM109 (pKSSE5.3) was thus selected for further studies.

In parallel, under the same conditions as described above and using glucose as growth substrate, the effect of the $4 \mathrm{HB}$ concentration on cell growth and $\mathrm{P} 4 \mathrm{HB}$ production was investigated. When the modified E2 medium was supplemented with $\mathrm{Na}-4 \mathrm{HB}$ as the sole carbon source, no growth was observed for E. coli JM109 (pKSSE5.3), demonstrating that $\mathrm{Na}-4 \mathrm{HB}$ cannot be utilized by $E$. coli JM109 as carbon source for growth. The optimum concentration of $\mathrm{Na}-4 \mathrm{HB}$ for $\mathrm{P} 4 \mathrm{HB}$ production was found to be between $2 \mathrm{~g} \mathrm{~L}^{-1}$ and $4 \mathrm{~g} \mathrm{~L}^{-1}$. Outside this range either low amounts of $\mathrm{P} 4 \mathrm{HB}$ were obtained, or growth inhibition took place (Table 1). Therefore, $4 \mathrm{~g} \mathrm{~L}^{-1} \mathrm{Na}-4 \mathrm{HB}$ was used in subsequent experiments.

\section{Comparison of carbon sources for P4HB synthesis in JM109 (pKSSE5.3)}

To produce $\mathrm{P} 4 \mathrm{HB}$ under better controlled conditions, the selected JM109 (pKSSE5.3) was cultivated in a $1 \mathrm{~L}$ bioreactor using modified E2 minimal medium containing xylose and 4HB. For comparison, glucose and glycerol were used as growth substrates, respectively.

Table 2 shows that the cells grown on xylose and glucose reached a similar maximal $\mathrm{OD}_{600}$ with a similar specific growth rate. More $\mathrm{P} 4 \mathrm{HB}$ was produced on $\mathrm{xy}$ lose $\left(32 \% \mathrm{w} \mathrm{w}^{-1}\right)$ than on glucose $\left(19 \% \mathrm{w} \mathrm{w}^{-1}\right)$. Grown on glycerol, the recombinant strain reached a much higher biomass than on glucose or xylose. This difference cannot be caused by $\mathrm{P} 4 \mathrm{HB}$ accumulation because the cells synthesized only $12 \%\left(\mathrm{w} \mathrm{w}^{-1}\right)$ of $\mathrm{P} 4 \mathrm{HB}$ on glycerol, which is much lower than those found during growth on either glucose or xylose. This result indicates that more carbon source is channeled to biomass when grown on glycerol under the used conditions. The achieved P4HB concentration of $0.41 \mathrm{~g} \mathrm{~L}^{-1}$ from glycerol was also lower than that from xylose $\left(0.65 \mathrm{~g} \mathrm{~L}^{-1} \mathrm{P} 4 \mathrm{HB}\right)$.

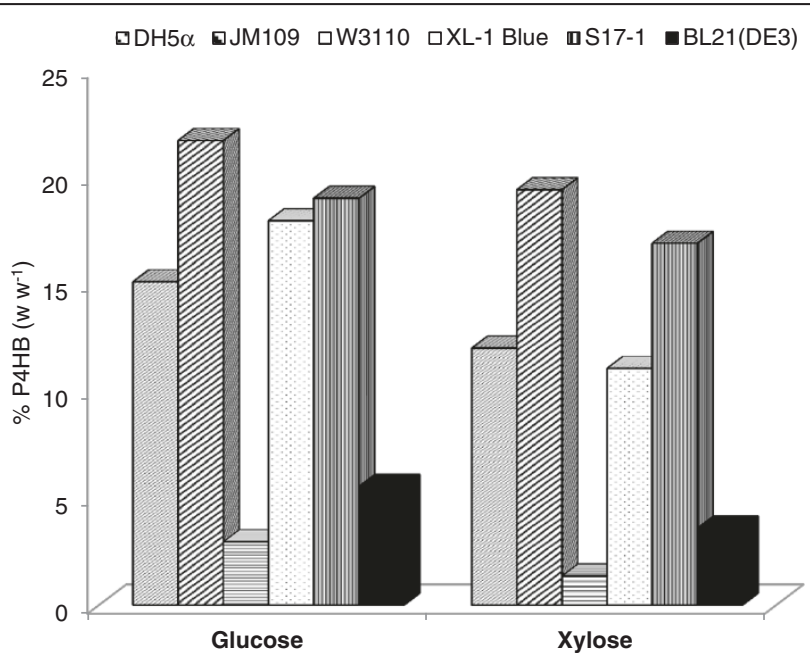

\begin{tabular}{|c|c|c|c|c|c|c|}
\hline \multirow[t]{2}{*}{ Strains } & \multicolumn{3}{|c|}{ Glucose } & \multicolumn{3}{|c|}{ Xylose } \\
\hline & $\mathrm{OD}_{600} \max$ & $\%$ P4HB w w ${ }^{-1}$ & $\mu\left(\mathrm{h}^{-1}\right)$ & $\mathrm{OD}_{600} \max$ & $\%$ P4HB w w ${ }^{-1}$ & $\mu\left(h^{-1}\right)$ \\
\hline $\mathrm{DH} 5 \alpha$ & $4.3 \pm 0.05$ & $15 \pm 4.8$ & $0.36 \pm 0.00$ & $1.9 \pm 0.2$ & $12 \pm 2.8$ & $0.09 \pm 0.04$ \\
\hline JM109 & $3.3 \pm 0.17$ & $22 \pm 0.2$ & $0.28 \pm 0.00$ & $2.4 \pm 0.6$ & $19 \pm 0.7$ & $0.28 \pm 0.05$ \\
\hline W3110 & $6.2 \pm 0.09$ & $3 \pm 3.3$ & $0.38 \pm 0.00$ & $5.9 \pm 0.0$ & $1 \pm 0.3$ & $0.31 \pm 0.05$ \\
\hline XL1-Blue & $3.3 \pm 0.58$ & $18 \pm 2.3$ & $0.28 \pm 0.02$ & $1.9 \pm 1.7$ & $11 \pm 1.8$ & $0.08 \pm 0.13$ \\
\hline $\mathrm{S} 17-1$ & $4.8 \pm 0.77$ & $19 \pm 0.5$ & $0.34 \pm 0.05$ & $3.1 \pm 0.3$ & $17 \pm 0.2$ & $0.19 \pm 0.16$ \\
\hline BL21(DE3) & $7.3 \pm 0.01$ & $6 \pm 4.9$ & $0.66 \pm 0.00$ & $6.3 \pm 0.3$ & $4 \pm 2.9$ & $0.41 \pm 0.01$ \\
\hline
\end{tabular}

Figure 1 Comparison of $\mathrm{P} 4 \mathrm{HB}$ accumulation in six recombinant $\boldsymbol{E}$. coli strains. Cultures were grown in shake flasks at $37^{\circ} \mathrm{C}$ in modified $\mathrm{E} 2$ minimal medium containing either glucose or xylose $\left(10 \mathrm{~g} \mathrm{~L}^{-1}\right)$. Error bars represent the standard deviations from four independent measurements. There is a significant difference from t-test in the P4HB accumulation between the strains growing on glucose and on xylose with $\mathrm{t}(5)$ value of 3.71 and $p<0.01$. 
Table 1 Influence of Na-4HB concentrations on P4HB accumulation in E. coli JM109 (pKSSE5.3)

\begin{tabular}{cccc}
\hline Na-4HB $\left(\mathbf{g ~ L}^{-\mathbf{1}}\right)$ & $\mathbf{O D}_{\text {600max }}$ & \%P4HB $\left(\mathbf{w ~} \mathbf{w}^{\mathbf{- 1}}\right)$ & $\boldsymbol{\mu}\left(\mathbf{h}^{-\mathbf{1}}\right)$ \\
\hline 1 & $1.77 \pm 0.08$ & $2 \pm 0.1$ & $0.32 \pm 0.01$ \\
2 & $1.88 \pm 0.02$ & $21 \pm 0.4$ & $0.34 \pm 0.02$ \\
4 & $1.94 \pm 0.04$ & $23 \pm 0.7$ & $0.33 \pm 0.01$ \\
6 & $1.93 \pm 0.06$ & $21 \pm 0.9$ & $0.22 \pm 0.01$ \\
\hline
\end{tabular}

The cells were grown at $37^{\circ} \mathrm{C}$ for $30 \mathrm{~h}$ in shake flasks containing modified E2 medium supplemented with $10 \mathrm{~g} \mathrm{~L}^{-1}$ glucose, $1 \mathrm{~g} \mathrm{~L}^{-1} \mathrm{NZ}$-amines and $100 \mathrm{\mu g} \mathrm{mL}^{-1}$ ampicillin. The standard deviations were obtained from three independent measurements.

\section{Influence of temperature on growth and P4HB accumulation}

Optimal temperature should support cell growth as well as product formation. Therefore, the influence of temperatures at $30,32,34$ and $37^{\circ} \mathrm{C}$ on growth and $\mathrm{P} 4 \mathrm{HB}$ accumulation was investigated. As expected, with the increase of temperature the specific growth rate increased correspondingly (Figure 2). Temperature also displayed a significant impact on $\mathrm{P} 4 \mathrm{HB}$ accumulation and the best temperature was found to be $32^{\circ} \mathrm{C}$ where about $37 \%\left(\mathrm{w} \mathrm{w}^{-1}\right)$ of $\mathrm{P} 4 \mathrm{HB}$ was produced after $24 \mathrm{~h}$ of cultivation. Temperatures below or above $32^{\circ} \mathrm{C}$ resulted in considerable decrease in $\mathrm{P} 4 \mathrm{HB}$ content (Figure 2). Thus, cultivation temperature was set to $32^{\circ} \mathrm{C}$ for subsequent experiments.

\section{Impact of the precursor addition at different physiological growth stages on P4HB synthesis}

Previously, it was found that addition of the precursor $4 \mathrm{HB}$ at the beginning of cultivation was best for P4HB synthesis [20]. The authors stated that addition of $4 \mathrm{HB}$ at the late exponential growth phase led to considerably lower cell mass reached and less $\mathrm{P} 4 \mathrm{HB}$ accumulation due to the limited availability of CoA [20]. To investigate whether P4HB synthesis in the E. coli JM109 recombinant is related to cell growth (i.e., CoA availability), we conducted the following experiment: E. coli JM109 (pKSSE5.3) was grown on modified E2 medium containing xylose in a $1 \mathrm{~L}$ bioreactor at

Table 2 Comparison of carbon sources for growth and P4HB accumulation of E. coli JM109 (pKSSE5.3)

\begin{tabular}{cccc}
\hline Carbon source & Xylose & Glucose & Glycerol \\
\hline $\mathrm{OD}_{600}$ & $3.4 \pm 1.4$ & $3.9 \pm 1.1$ & $7.6 \pm 0.4$ \\
$\mathrm{CDW}\left(\mathrm{g} \mathrm{L}^{-1}\right)$ & $2.16 \pm 0.37$ & $2.04 \pm 0.60$ & $3.80 \pm 0.18$ \\
$\mu\left(\mathrm{h}^{-1}\right)$ & $0.32 \pm 0.09$ & $0.38 \pm 0.04$ & $0.35 \pm 0.01$ \\
$\mathrm{P} 4 \mathrm{HB}$ content\% $\left(\mathrm{W} \mathrm{W}^{-1}\right)$ & $32 \pm 3.7$ & $19 \pm 6.4$ & $12 \pm 3.6$ \\
P4HB concentration $\left(\mathrm{g} \mathrm{L}^{-1}\right)$ & $0.65 \pm 0.11$ & $0.36 \pm 0.05$ & $0.41 \pm 0.00$
\end{tabular}

The cells were cultivated in a $1 \mathrm{~L}$ bioreactors at $37^{\circ} \mathrm{C}$ with an agitation of $500 \mathrm{rpm}$ in modified E2 minimal medium supplemented with $4 \mathrm{~g} \mathrm{~L}^{-1} \mathrm{Na}-4 \mathrm{HB}$, $1 \mathrm{~g} \mathrm{~L}^{-1} \mathrm{NZ}$-amines, $100 \mu \mathrm{g} \mathrm{mL}^{-1}$ ampicillin and $0.015 \mathrm{~g} \mathrm{~L}^{-1}$ thiamine. Xylose, glucose or glycerol was used as the growth substrate. The growth was followed with time and samples were taken after $25 \mathrm{~h}$ for P4HB analysis. The data were obtained from two independent cultivations. $32^{\circ} \mathrm{C}$, and $4 \mathrm{~g} \mathrm{~L}^{-1}$ of $\mathrm{Na}-4 \mathrm{HB}$ was added to the culture at the beginning (culture I), at the end of the exponential phase (culture II), or by a combination of $2 \mathrm{~g} \mathrm{~L}^{-1}$ at the beginning and $2 \mathrm{~g} \mathrm{~L}^{-1}$ at the end of the exponential phase (culture III) (Figure 3A). The results obtained demonstrate that addition of $4 \mathrm{HB}$ at different growth phases influenced neither specific growth rate of the culture nor P4HB synthesis (Figure 3A). Cells in all cultures exhibited a specific growth rate of about $0.34 \mathrm{~h}^{-1}$ in the first $8 \mathrm{~h}$ of cultivation. In all cultures the initiation of $\mathrm{P} 4 \mathrm{HB}$ synthesis was only at the end of the exponential growth phase, even when $4 \mathrm{HB}$ was provided at the beginning (cultures I and III). During the accumulation phase, P4HB content increased exponentially with a similar rate in all three cultures and to the same extent for about $24 \mathrm{~h}$ in all cultures (Figure 3B). Afterwards the P4HB accumulation slowed down until the end of cultivation $(55 \mathrm{~h})$, where the $\mathrm{P} 4 \mathrm{HB}$ content increased to a maximum of about $70 \%$ in cultures I and III and about $60 \%$ in culture II. It seems that P4HB content in culture II could potentially increase further, however, it was not possible likely due to a limitation of certain nutrients. The concentration of P4HB $\left(\mathrm{g} \mathrm{L}^{-1}\right)$ increased exponentially for $18 \mathrm{~h}$, starting from the initiation of $\mathrm{P} 4 \mathrm{HB}$ synthesis at the end of the first exponential growth phase (Figure 3B). Afterwards the increase of the $\mathrm{P} 4 \mathrm{HB}$ concentration slowed down and maximal about 3.7, 3.3 and $4.3 \mathrm{~g} \mathrm{~L}^{-1}$ of $\mathrm{P} 4 \mathrm{HB}$ was obtained in cultures I, II and III, respectively, at the end of the cultivation (Figure 3B). Correspondingly, cell density in all cultures also increased exponentially with the exponential increase of $\mathrm{P} 4 \mathrm{HB}$ synthesis (Figure 3A). The accumulation rate of $\mathrm{P} 4 \mathrm{HB}$ per cell dry weight was linear and similar in all three cultures with a value of about $0.025 \mathrm{~g} \mathrm{~g}^{-1} \mathrm{~h}^{-1}$ (Figure 3C).

The results obtained here demonstrate the following: 1) $\mathrm{P} 4 \mathrm{HB}$ synthesis only started at the end of the exponential growth phase, regardless of the stage in which the precursor $4 \mathrm{HB}$ was added (i.e., either at the beginning or at the end of the exponential growth phase); 2) P4HB content and concentration increased exponentially once the $\mathrm{P} 4 \mathrm{HB}$ synthesis was initiated; 3) The $\mathrm{P} 4 \mathrm{HB}$ accumulation rate per cell dry weight was similar regardless when the precursor $4 \mathrm{HB}$ was added (i.e. at the beginning or the end of the exponential growth phase); 4) The increase of biomass after the exponential growth phase was mainly due to the $\mathrm{P} 4 \mathrm{HB}$ accumulation; and 5) $\mathrm{P} 4 \mathrm{HB}$ accumulation stopped due to either nutritional limitation and/or product(s) inhibition. To obtain more information, a more detailed analysis on substrate consumption and product formation was performed.

\section{Batch culture for P4HB production}

E. coli JM109 (pKSSE5.3) was grown in a $1 \mathrm{~L}$ bioreactor on modified E2 medium containing xylose and $\mathrm{Na}-4 \mathrm{HB}$. The cells behaved in the same manner as described 


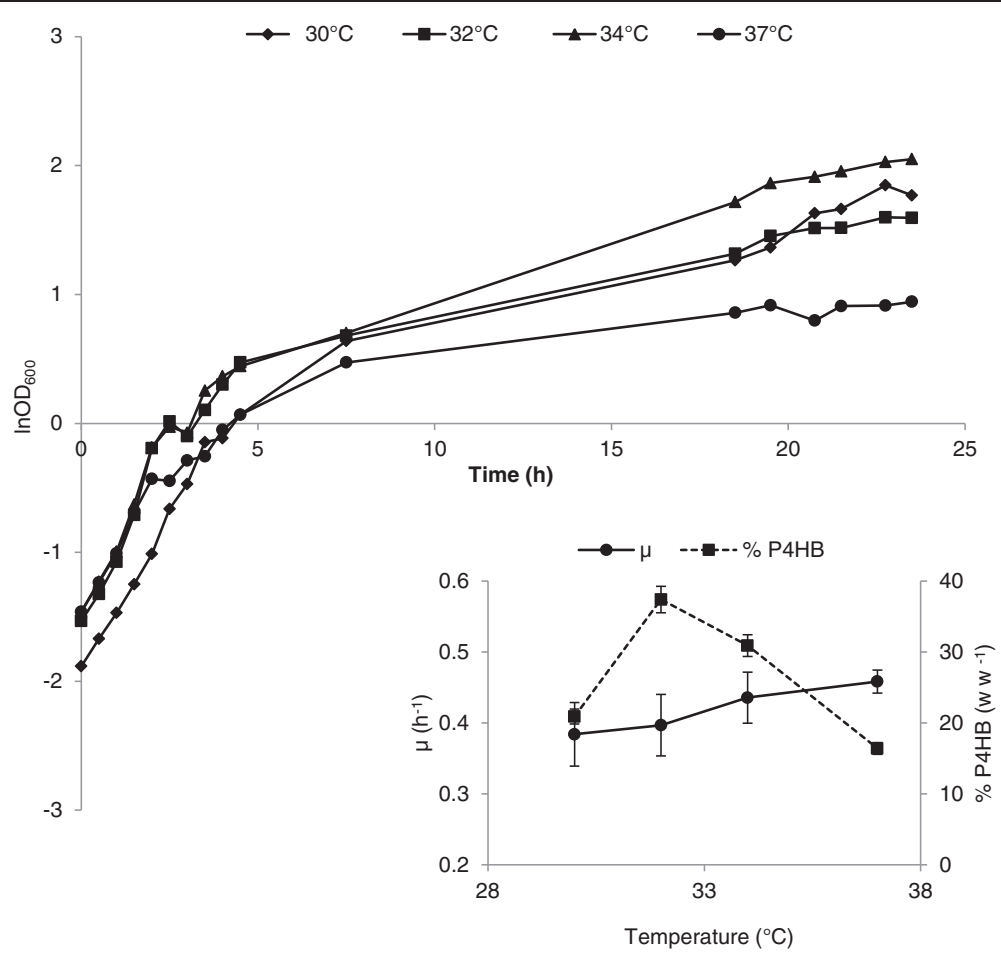

Figure 2 Influence of temperature on the growth and P4HB accumulation of E. coli JM109 (pKSSE5.3). The cells were grown in modified E2 minimal medium supplemented with $10 \mathrm{~g} \mathrm{~L}^{-1}$ xylose, $4 \mathrm{~g} \mathrm{~L}^{-1} \mathrm{Na}-4 \mathrm{HB}, 1 \mathrm{~g} \mathrm{~L}^{-1} \mathrm{NZ}$-amines, $100 \mathrm{\mu g} \mathrm{mL}^{-1}$ ampicillin and $0.015 \mathrm{~g} \mathrm{~L}^{-1}$ thiamine. Four different temperatures were tested: $30^{\circ} \mathrm{C}(\bullet), 32^{\circ} \mathrm{C}(\boldsymbol{\bullet}), 34^{\circ} \mathrm{C}(\boldsymbol{\Delta})$ and $37^{\circ} \mathrm{C}(\bullet)$. Error bars represent the deviations from two independent measurements.

above (see Figure 3) and three phases were observed (Figure 4). Phase 1: Growth phase $(0-11 \mathrm{~h})$. Cells grew exponentially with a specific growth rate of $0.28 \mathrm{~h}^{-1}$ for $11 \mathrm{~h}$. In this phase, xylose and nitrogen were consumed but were still in excess in the medium. No excretion of acids such as acetic, pyruvic or lactic acid was observed during this phase. Na-4HB was hardly consumed and only a small amount of P4HB was detected (below 3\% $\mathrm{w} \mathrm{w}^{-1}$ ). The observed termination of the exponential phase can be caused either by a limited availability of nutrient(s) or by product(s) inhibition under our experimental conditions. This limitation or inhibition appears to promote $\mathrm{P} 4 \mathrm{HB}$ synthesis. $\mathrm{O}_{2}$ limitation can be ruled out due to automatic control of the dissolved oxygen which was never below 30\% as described in Method section. Phase 2: P4HB accumulation phase $(11-35 \mathrm{~h})$. Similar to what found before, cells started to accumulate P4HB exponentially after phase 1 and $\mathrm{Na}-4 \mathrm{HB}$ was consumed and decreased in the culture from 3.8 to $1.4 \mathrm{~g} \mathrm{~L}^{-1}$. During this time, $\mathrm{P} 4 \mathrm{HB}$ content increased from 3\% to $58 \%$ $\left(\mathrm{w} \mathrm{w}^{-1}\right.$ ) and the total amount of P4HB increased from 0.024 to $2.76 \mathrm{~g} \mathrm{~L}^{-1}$ (Figure 4). The residual biomass kept almost constant during this phase. Xylose and nitrogen were further consumed and the culture reached carbon (xylose) limitation after $35 \mathrm{~h}$ of incubation, whereas there was still enough nitrogen left. In this phase, pyruvic acid and lactic acid were produced and reached maximal concentrations of $113 \mathrm{mg} \mathrm{L}^{-1}$ and $11 \mathrm{mg} \mathrm{L}^{-1}$, respectively, after $27 \mathrm{~h}$ of incubation. Both acids were further consumed and depleted from the medium after $35 \mathrm{~h}$ of incubation. Accumulation of pyruvic acid and lactic acid cannot be the reason for the transition from Phase 1 to Phase 2 because the concentrations of both acids were too low to be inhibiting [21]. Phase 3: Stagnation phase $(35-54$ h). Upon depletion of xylose no significant change in biomass and $\mathrm{P} 4 \mathrm{HB}$ content took place. The cells consumed neither the nitrate provided nor the Na-4HB completely. The P4HB accumulation rate was in the range of $0.027 \mathrm{~g} \mathrm{~g}^{-1} \mathrm{~h}^{-1}$, similar to that found in Figure 3. The consumed Na$4 \mathrm{HB}$ was almost completely converted into polymer with a yield $\mathrm{Y}_{\mathrm{P} 4 \mathrm{HB} / \mathrm{Na}-4 \mathrm{HB}}$ of $92 \% \mathrm{~g}$ of carbon from $\mathrm{P} 4 \mathrm{HB}$ per $\mathrm{g}$ of carbon from $\mathrm{Na}-4 \mathrm{HB}$.

\section{Discussion}

Despite the fact that bioprocesses for recombinant production of $\mathrm{P} 3 \mathrm{HB}$ in E. coli have been studied extensively [22,23], the biosynthesis of P4HB in E. coli has not been yet investigated in depth. Several reports have described the P4HB synthesis and accumulation in E. coli $[16,20,24]$. However, neither physiological and cultivation conditions, 


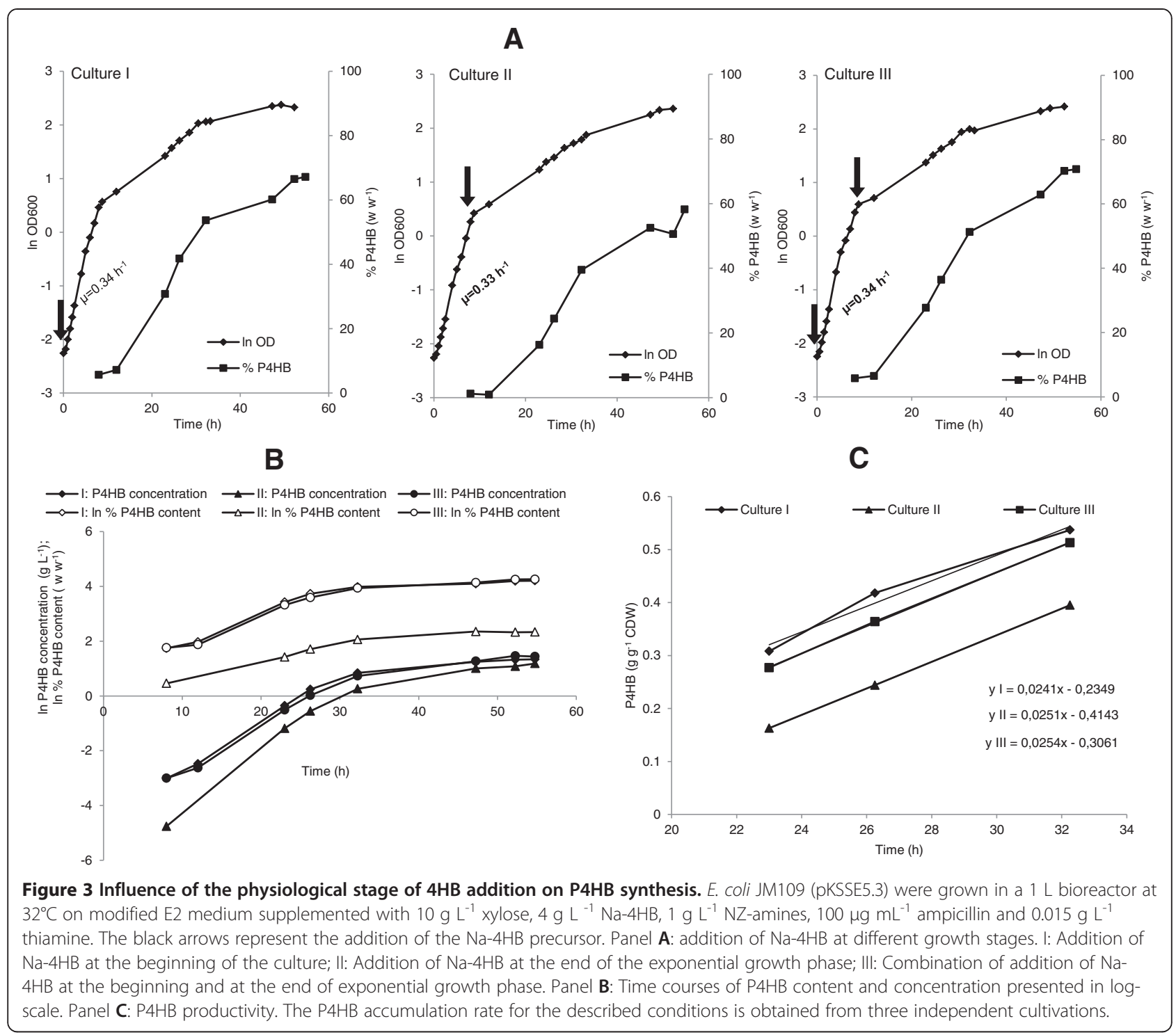

nor the external factors that may influence P4HB accumulation have been studied yet in detail. For this reason, we attempted to address two issues in this work. The first issue was whether or not $\mathrm{P} 4 \mathrm{HB}$ can be produced from $\mathrm{Na}-4 \mathrm{HB}$ efficiently in combination with xylose as growth substrate. The second issue was to tackle how P4HB synthesis can be stimulated. Our results demonstrate that $\mathrm{P} 4 \mathrm{HB}$ can be synthesized efficiently by combining xylose and $4 \mathrm{HB}$ and its production can be enhanced reproducibly by an unknown factor, either nutrient depletion or product inhibition.

To reach efficient $\mathrm{P} 4 \mathrm{HB}$ production, cultures exhibiting high specific growth rate, high biomass concentration and high levels of P4HB content are desired. Since the metabolic status, including the concentrations of metabolites and the rate of metabolite formation may be different from one strain to another, it is very understandable that rates of $\mathrm{P} 4 \mathrm{HB}$ synthesis and levels of $\mathrm{P} 4 \mathrm{HB}$ accumulation will be different from one to another. Previously, it has been reported that $\mathrm{P} 3 \mathrm{HB}$ production can differ dramatically by using different $E$. coli strains, e.g. the wild-type $E$. coli $\mathrm{K} 12$ synthesized $0.4 \mathrm{~g} \mathrm{~L}^{-1} \mathrm{P} 3 \mathrm{HB}$, whereas XL1-Blue produced $7.2 \mathrm{~g} \mathrm{~L}^{-1}$ P3HB under the same conditions [23]. In this study, we have chosen six E. coli strains originated from B strain (BL21(DE3)) and K12 strains including the wild type (W3110) and the K12 derivatives (DH5 $\alpha$, JM109, XL1-Blue, S17-1). JM109 seems to have the best physiological background for $\mathrm{P} 4 \mathrm{HB}$ synthesis, whereas the worst performers were W3110 and BL21(DE3). The latter two strains grew fast, and used the carbon source mainly for biomass formation but produced little amount of P4HB (Figure 1).

Previously it has been reported that using E. coli XL1Blue carrying pKSSE5.3, a P4HB concentration of about 


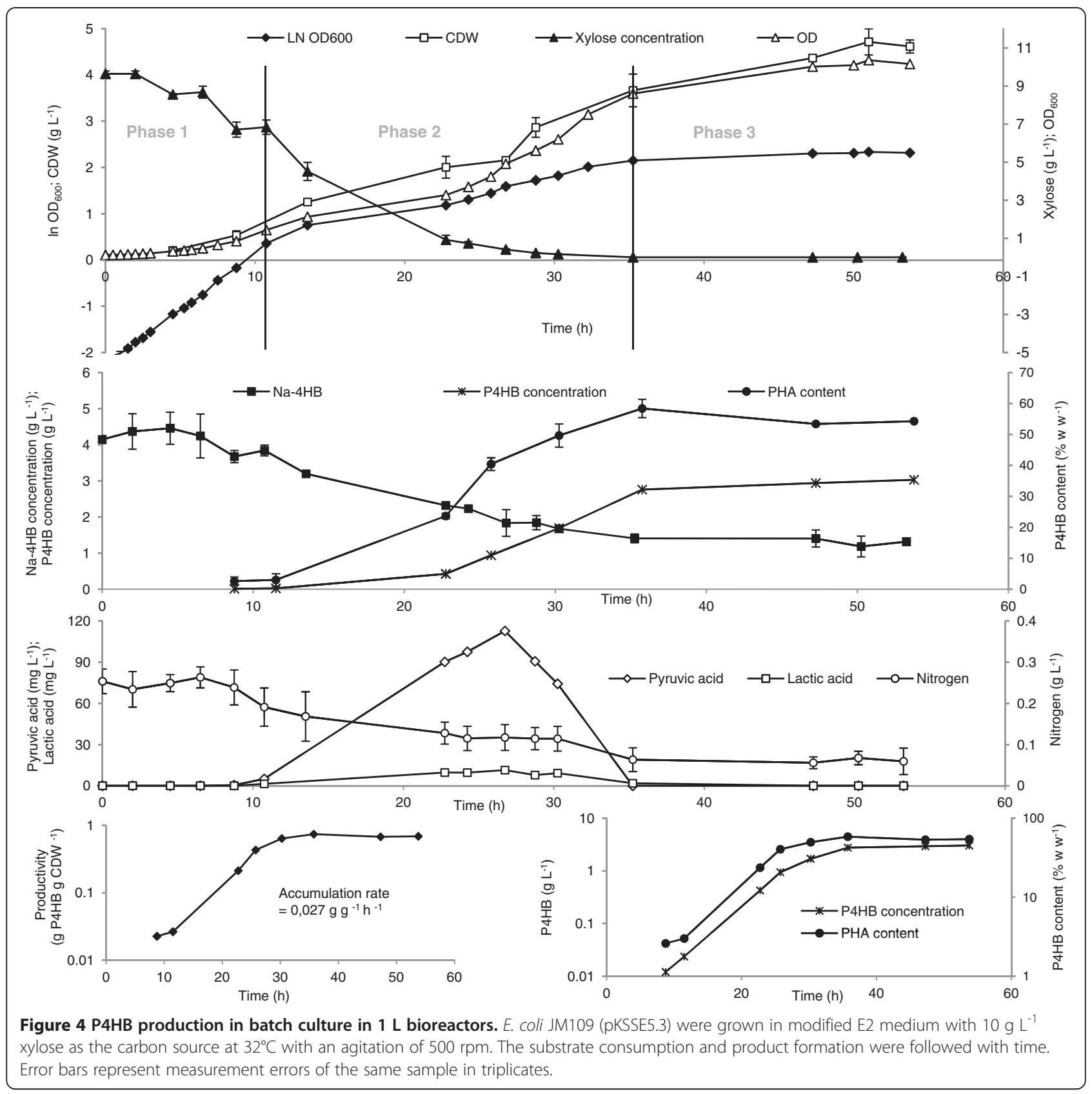

$4.0 \mathrm{~g} \mathrm{~L} \mathrm{~L}^{-1}$ and $\mathrm{P} 4 \mathrm{HB}$ content of $36 \%\left(\mathrm{w} \mathrm{w}^{-1}\right)$ could be obtained by a fed-batch culture on M9 medium containing glucose and yeast extract and $18 \mathrm{~g} \mathrm{~L}^{-1}$ of $4 \mathrm{HB}$ [20]. The conversion yield of the precursor $4 \mathrm{HB}$ to $\mathrm{P} 4 \mathrm{HB}$ (g carbon : g carbon) was about 24\%. Recently, Zhou et al. reported that E. coli JM109 mutant carry two plasmids reached about $1.9 \mathrm{~g} \mathrm{~L}^{-1} \mathrm{P} 4 \mathrm{HB}$ and $35 \%\left(\mathrm{w} \mathrm{w}^{-1}\right)$ $\mathrm{P} 4 \mathrm{HB}$ using $\mathrm{LB}$ rich medium containing glucose in a batch culture [17]. Two antibiotics were needed to keep the plasmids and LB rich medium is costly. The authors also showed that in a fed-batch fermentation $7.5 \mathrm{~g} \mathrm{~L}^{-1}$ P4HB could be achieved by using LB medium containing a total of $90 \mathrm{~g} \mathrm{~L}^{-1}$ glucose after 52 hours [17]. The conversion yield of the precursor glucose to P4HB (g carbon : g carbon) was about $10.5 \%$. In the current study, we achieved $4.3 \mathrm{~g} \mathrm{~L}^{-1} \mathrm{P} 4 \mathrm{HB}$ and $67 \%\left(\mathrm{w} \mathrm{w}^{-1}\right)$ P4HB in a batch culture using the described medium. The consumption of the precursor $4 \mathrm{HB}$ was almost complete with a conversion yield $\mathrm{Y}_{\mathrm{P} 4 \mathrm{HB} / \mathrm{Na}-4 \mathrm{HB}}$ of $92 \% \mathrm{~g} \mathrm{~g}^{-1}$. Even though the cost of $4 \mathrm{HB}$ is higher than glucose, the price of $4 \mathrm{HB}$ can be significantly reduced by using gamma-butyrolactone as the precursor for chemical synthesis of $4 \mathrm{HB}$ (see Methods section). Hence, the process developed here is an efficient approach for $\mathrm{P} 4 \mathrm{HB}$ production. 
In earlier studies, addition of $4 \mathrm{HB}$ at the beginning of a cultivation was found to be the best for cell growth and $\mathrm{P} 4 \mathrm{HB}$ production [20]. Here, we observed no difference in cell growth and $\mathrm{P} 4 \mathrm{HB}$ synthesis between adding $4 \mathrm{HB}$ at the beginning and at the end of the exponential growth phase (Figure 3). P4HB synthesis was initiated only at the end of exponential growth, even when $4 \mathrm{HB}$ was supplied right at the start. In contrast to $\mathrm{P} 3 \mathrm{HB}$ accumulation in $E$. coli, where the polymer is synthesized during cell growth [25], P4HB production has been found to be distinctly separated from exponential cell growth in our experiments. The end of exponential growth caused by either product inhibition or nutrient limitation stimulated $\mathrm{P} 4 \mathrm{HB}$ synthesis. It seems that the cell growth and $\mathrm{P} 4 \mathrm{HB}$ production compete with each other for the same nutrients. As indicated from the results shown in Figure 1, both W3110 and BL21(DE3) strains grew fast and reached high final biomass but accumulated only a negligible amount of P4HB. Furthermore, when the conditions are favored for cell growth e.g. at $37^{\circ} \mathrm{C}, \mathrm{P} 4 \mathrm{HB}$ is disadvantaged (Figure 2). These results suggest that nutrients are directed mainly into the tricarboxylic acid (TCA) cycle for cell growth rather than into P4HB synthesizing pathway. We also did not observe the accumulation of acetic acid during the whole cultivation period. This seems to be due to the efficient utilization of excessive acetyl-CoA for the synthesis of $\mathrm{P} 4 \mathrm{HB}$, which would otherwise form acetic acid [26].
Taking advantage of the knowledge acquired previously and our findings in this study, we propose a model to explain the metabolism of $\mathrm{P} 4 \mathrm{HB}$ synthesis in recombinant E. coli: Introducing PHA synthase (PhaC) from $R$. eutropha and 4-hydroxybutyrate CoA-transferase (OrfZ) from C. kluyveri into $E$. coli would result in the establishment of a new metabolic pathway, which competes with several existing pathways leading to citrate and acetate formation and to fatty acid synthesis (Figure 5). When the available nutrients and energy are used for cell growth, P4HB would hardly be synthesized. When the cell growth slows down / stops due to nutrient limitation other than carbon starvation, $\mathrm{P} 4 \mathrm{HB}$ synthesis can then be initiated. The reduction or stop of cell growth cannot be caused by carbon limitation because the cells still need the essential nutrients for maintenance. When xylose limitation occurred, P4HB synthesis also terminated (Figure 4).

\section{Conclusions}

In this study, we compared for the first time different E. coli strains with respect to growth on xylose and $\mathrm{P} 4 \mathrm{HB}$ accumulation. Different growth conditions were also investigated such as temperature and the cell physiological stages for $\mathrm{P} 4 \mathrm{HB}$ synthesis. Unlike what has been reported previously, the P4HB synthesis was found to be separated from the cell growth, namely $\mathrm{P} 4 \mathrm{HB}$ synthesis mainly takes place after the end of the exponential growth phase. Under the tested conditions, $\mathrm{P} 4 \mathrm{HB}$ contents in the range of 58 to

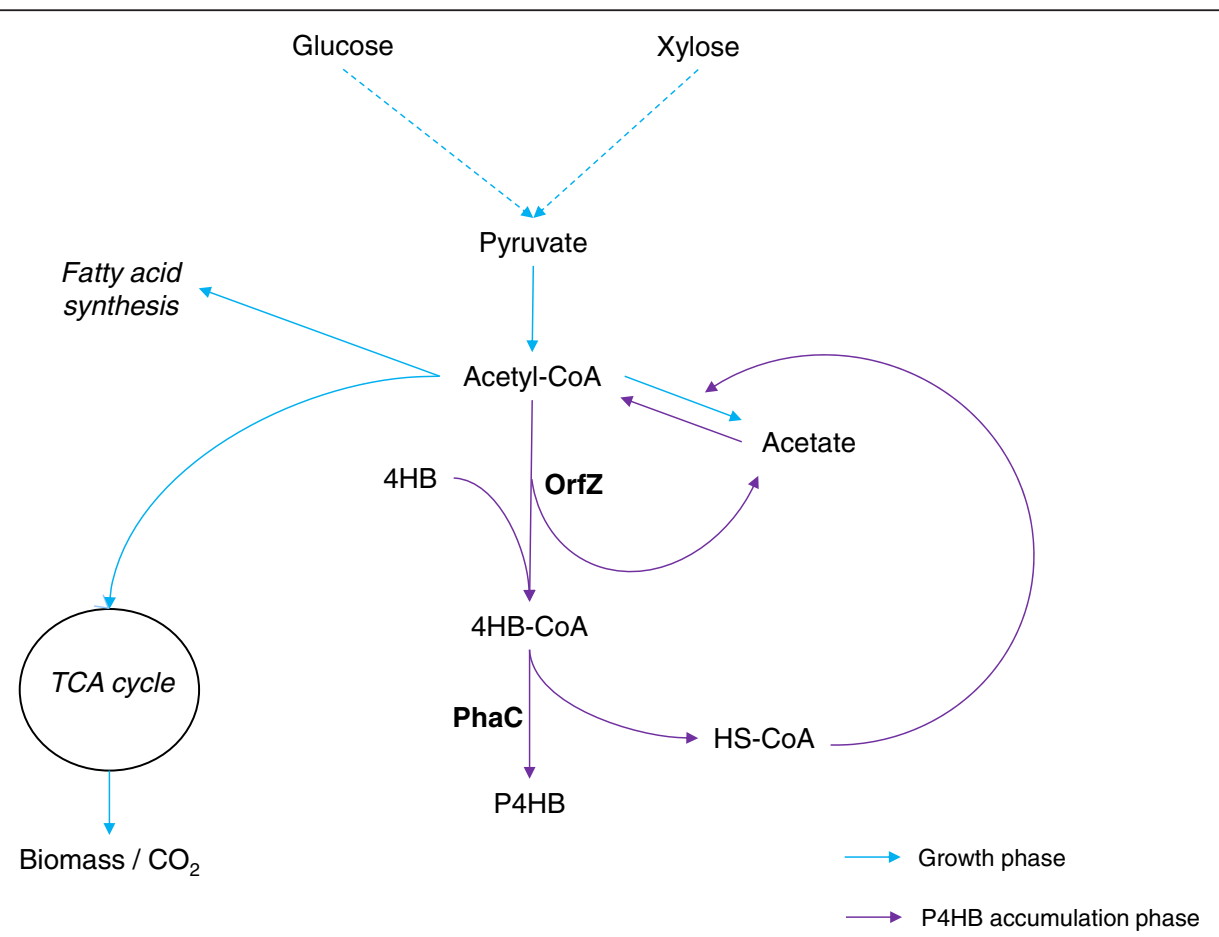

Figure 5 Hypothetic metabolic pathway of P4HB synthesis from Na-4HB in recombinant E. coli. Blue color represents growth phase, purple color represents $\mathrm{P} 4 \mathrm{HB}$ synthesis phase. 
$70 \%\left(\mathrm{w} \mathrm{w}^{-1}\right)$ and $\mathrm{P} 4 \mathrm{HB}$ concentrations in the range of 2.8 to $4.3 \mathrm{~g} \mathrm{~L}^{-1}$ were obtained with a conversion yield $\mathrm{Y}_{\mathrm{P} 4 \mathrm{HB} /}$ Na4HB of $92 \% \mathrm{w} \mathrm{w}^{-1}$. These results were achieved here by simple batch culture, which was only possible previously through fed-batch high cell density cultures. However, to further improve the productivity of $\mathrm{P} 4 \mathrm{HB}$ production process for practical industrial applications, high cell density cultures will need to be investigated and employed.

\section{Methods}

\section{Bacterial strains and plasmids}

The E. coli strains used in this study are listed in Table 3. Among them, XL1-Blue, S17-1 and JM109 were previously used for P4HB production [16,20,24], and thus were selected here for comparison purpose. The previously constructed plasmid pKSSE5.3 carrying a PHA synthase gene (phaC) from $R$. eutropha and a 4-hydroxybutyric acidcoenzyme A transferase gene (orf $Z$ ) from $C$. kluyveri was used in this study [16].

\section{Chemicals, media and cultivation conditions Chemicals}

All chemicals were purchased from Sigma-Aldrich (Buchs, Switzerland).

\section{Synthesis of $\mathrm{Na}-4 \mathrm{HB}$}

One of the simplest and low-cost ways to obtain $4 \mathrm{HB}$ is by hydrolysis of the corresponding lactone to the desired hydroxy acid. The reaction was proceeded with equal molar of gamma-butyrolactone and $\mathrm{NaOH}$ [33]. In detail: $4 \mathrm{M}$ $\mathrm{NaOH}$ solution was prepared and mixed slowly to $4 \mathrm{M}$ of gamma-butyrolactone on ice. After the reaction mixture was cooled down to room temperature, it was analyzed by HPLC/MS ([34], also see below). An almost $100 \%$ conversion of gamma-butyrolactone to $\mathrm{Na}-4 \mathrm{HB}$ was achieved.

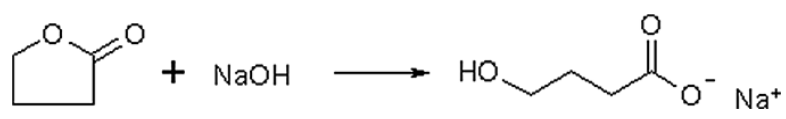

Gamma-butyrolactone $+\mathrm{NaOH} \rightarrow \mathrm{Na}-4 \mathrm{HB}$.

\section{Media}

E. coli strains were cultivated overnight in LB medium with $100 \mu \mathrm{g} \mathrm{mL} \mathrm{m}^{-1}$ ampicillin. This culture was used to inoculate the preculture containing modified E2 medium [35]. Modified E2 medium contained the following constituents: $\mathrm{NaNH}_{4} \mathrm{HPO}_{4} \cdot 4 \mathrm{H}_{2} \mathrm{O} 3.5 \mathrm{~g} \mathrm{~L}^{-1}$, $\mathrm{KH}_{2} \mathrm{PO}_{4} 3.7 \mathrm{~g} \mathrm{~L}^{-1}, \mathrm{~K}_{2} \mathrm{HPO}_{4} 7.5 \mathrm{~g} \mathrm{~L}^{-1}$, dissolved in $1 \mathrm{~L}$ of water. One $\mathrm{mL} \mathrm{L}^{-1}$ of $1 \mathrm{M} \mathrm{MgSO}_{4} \cdot 7 \mathrm{H}_{2} \mathrm{O}$ was added to the medium. One $\mathrm{mL} \mathrm{L}^{-1}$ of trace elements (TE) dissolved in $1 \mathrm{M} \mathrm{HCl}$ was also added. TE contained: $\mathrm{FeSO}_{4} \cdot 7 \mathrm{H}_{2} \mathrm{O} \quad 2.78 \mathrm{~g} \mathrm{~L} \mathrm{~L}^{-1}, \mathrm{CaCl}_{2} \cdot 2 \mathrm{H}_{2} \mathrm{O} \quad 1.47 \mathrm{~g} \mathrm{~L}^{-1}$, $\mathrm{MnCl}_{2} \cdot 4 \mathrm{H}_{2} \mathrm{O} 1.98 \mathrm{~g} \mathrm{~L}^{-1}, \mathrm{CoCl}_{2} \cdot 6 \mathrm{H}_{2} \mathrm{O} 2.38 \mathrm{~g} \mathrm{~L}^{-1}$, $\mathrm{CuCl}_{2} \cdot 2 \mathrm{H}_{2} \mathrm{O} 0.17 \mathrm{~g} \mathrm{~L}^{-1}, \mathrm{ZnSO}_{4} \cdot 7 \mathrm{H}_{2} \mathrm{O} 0.29 \mathrm{~g} \mathrm{~L}^{-1}$. Xylose, glucose or glycerol $\left(10 \mathrm{~g} \mathrm{~L}^{-1}\right)$ was used as the sole carbon source.

\section{Growth in shake flasks}

Growth studies were performed in $1 \mathrm{~L}$ shake flasks containing $200 \mathrm{~mL}$ of modified E2 medium and $10 \mathrm{~g} \mathrm{~L}^{-1}$ of a carbon source. $1 \mathrm{~g} \mathrm{~L}^{-1}$ of NZ-amines and $100 \mu \mathrm{g} \mathrm{mL} \mathrm{m}^{-1}$ of ampicillin were added to the minimal medium. $\mathrm{Na}-4 \mathrm{HB}$ (1 to $6 \mathrm{~g} \mathrm{~L}^{-1}$ according to the experiment) was added as $\mathrm{P} 4 \mathrm{HB}$ precursor as indicated in individual experiments.

\section{Culture in 1 L bioreactors}

Four $1 \mathrm{~L}$ reactor cultures were grown in parallel in Multifors benchtop bioreactors (Infors AG, Bottmingen, Switzerland). Temperature was controlled at $32^{\circ} \mathrm{C}$ with an external circulating water bath, and $\mathrm{pH}$ was maintained at $7.0+/-0.1$ by automatic addition of $25 \%$ $\mathrm{NaOH}$ or $30 \% \mathrm{H}_{3} \mathrm{PO}_{4}$. Dissolved oxygen tension was monitored continuously with an oxygen probe (Infors AG, Bottmingen, Switzerland) and kept always above $30 \%$ oxygen saturation. The agitation was set at $500 \mathrm{rpm}$. Each reactor was inoculated using a preculture prepared as described above in "Growth in shake flasks". The initial $\mathrm{OD}_{600}$ value in bioreactors was between 0.10 and

Table 3 E. coli strains and plasmid used in this study

\begin{tabular}{|c|c|c|}
\hline Strains & Relevant characteristics & References \\
\hline $\mathrm{DH} 5 \mathrm{a}$ & 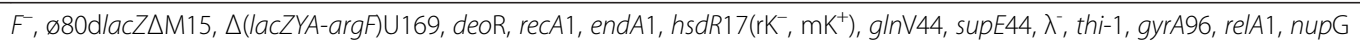 & [27] \\
\hline JM109 & 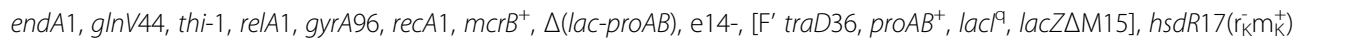 & [28] \\
\hline XL-1 Blue & 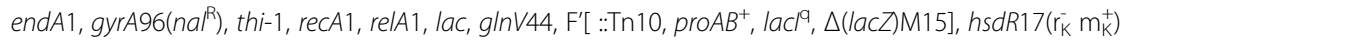 & [29] \\
\hline S17-1 & tmpR, spcR, strR, recA pro hsdR RP4-2-Tc::Mu-Km::Tn7 & [30] \\
\hline W3110 & $F_{,-}^{-} \lambda^{-}, r p h-1, I N V(r r n D, r r n E)$ & [31] \\
\hline BL21(DE3) & $F$, ompT, gal, dcm, lon, hsdS $\left(r_{B} m_{B}^{-}\right), \lambda(D E 3)$, [lacl lacUV5-T7 gene 1 ind1 sam7 nin5]) & [32] \\
\hline \multicolumn{3}{|l|}{ Plasmid } \\
\hline pKSSE5.3 & phaC, orfZ, Ampr & [16] \\
\hline
\end{tabular}


0.30. The modified E2 medium was used to perform all the growth studies in $1 \mathrm{~L}$ reactors supplemented with $10 \mathrm{~g} \mathrm{~L}^{-1}$ of carbon source, $1 \mathrm{~g} \mathrm{~L}^{-1}$ of NZ-amines, $4 \mathrm{~g} \mathrm{~L}^{-1}$ of $\mathrm{Na}-4 \mathrm{HB}$ and $0.015 \mathrm{~g} \mathrm{~L}^{-1}$ of thiamine. Ampicillin was added to a final concentration of $100 \mu \mathrm{g} \mathrm{mL} \mathrm{m}^{-1}$ to maintain the pKSSE5.3 plasmid.

\section{Analytical methods \\ Cell concentration}

Growth of bacterial cells was followed by measuring optical density at $600 \mathrm{~nm}\left(\mathrm{OD}_{600}\right)$ using a UV spectrophotometer (Genesys 6, ThermoSpectronic, Switzerland).

Cell dry weight was determined either by using pre-weighed polycarbonate filters (pore size $0.2 \mu \mathrm{m}$, Whatman, Scheicher \& Schuell, Dassel, Germany) or by pre-weighed $2 \mathrm{~mL}$ Eppendorf tubes. In the first method, an appropriate volume $(0.5$ to $5 \mathrm{~mL})$ of culture was filtered in order to obtain a biomass dry weight of about $2 \mathrm{mg}$ per filter. The filter was dried overnight at $100^{\circ} \mathrm{C}$, cooled down to room temperature in a desiccator and then weighed. In the second method, $2 \mathrm{~mL}$ of culture broth was centrifuged at 12,000 g for $2 \mathrm{~min}$ in a $2 \mathrm{~mL}$ pre-weighed Eppendorf tube. The supernatant was discarded and the cell pellet was dried overnight at $100^{\circ} \mathrm{C}$ and cooled down to room temperature in a desiccator. The $2 \mathrm{~mL}$ Eppendorf tube was then weighed. For both methods, the weight difference was used to determine the dry biomass.

\section{PHA content}

PHA content and composition were determined according to a method described previously [36]. Methylene chloride containing benzoic acid $\left(0.1 \mathrm{~g} \mathrm{~L}^{-1}\right)$ was used as internal standard. Own lab purified $\mathrm{P} 4 \mathrm{HB}$ was used for obtaining standard curves. $\mathrm{Na}_{2} \mathrm{CO}_{3}$ powder was added to dry the extracted chlorinated solvent phase. The samples were analyzed by gas chromatography (GC) (A200s, Trace GC 2000 series, Fisons Instruments, Rodano, Italy) equipped with a polar fused silica capillary column (Supelcowax-10: length $30 \mathrm{~m}$; inside diameter $0.31 \mathrm{~mm}$; film thickness $0.5 \mu \mathrm{m}$; Supelco, Buchs, Switzerland) [37]. P4HB was depolymerized, esterified and methylated, leading to three different peaks in the GC chromatogram. These three peaks were also observed by Hein and coworkers when P4HB homopolymers were analyzed [16].

\section{Nitrogen concentration}

$\mathrm{NH}_{4}^{+}$-nitrogen consumption was detected using an ammonium test kit following the manufacturer instruction (Merck KGaA, 64271 Darmstadt, Germany). The detection limit was $0.01 \mathrm{NH}_{4}^{+}$-nitrogen $\mathrm{mg} \mathrm{L}^{-1}$. The method was linear up to $3.0 \mathrm{mg} \mathrm{L}^{-1}$, above which dilution with distilled water was needed. The results obtained are in $\mathrm{mg} \mathrm{L}^{-1}$ of nitrogen.

\section{Measurement of xylose, Na-4HB, acetate, pyruvate and lactate}

Concentrations of xylose, $\mathrm{Na}-4 \mathrm{HB}$ and acetate in the culture medium were measured by HPLC/MS. Supernatant resulting from culture centrifugation at 12,000 $\mathrm{g}$ for $2 \mathrm{~min}$ was diluted to a concentration between 0.01 and $0.1 \mathrm{mM}$ with distilled water, filtrated through a Titan HPLC filter $(0.45 \mu \mathrm{m}$, Infochroma AG, Zug, Switzerland), and loaded on a reversed phase C18 column (Gemini C18 5 micron, $250 \mathrm{~mm} \times 4.60 \mathrm{~mm}$, Phenomenex, U.K.). A gradient of $100 \%$ of diluted formic acid ( $0.1 \mathrm{v} \%$ in water) to $100 \%$ of acetonitrile was applied as the mobile phase. The flow rate was

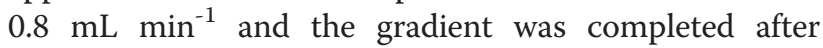
25 minutes. The peaks were detected by electrospray ionization (ESI) in negative mode [34]. Standard curves for xylose, $\mathrm{Na}-4 \mathrm{HB}$ and acetate were recorded in the range of 0.01 to $1.00 \mathrm{~g} \mathrm{~L}^{-1}, 0.01 \mathrm{~g} \mathrm{~L}^{-1}$ to $0.20 \mathrm{~g} \mathrm{~L}^{-1}$ and 0.01 to $1.00 \mathrm{~g} \mathrm{~L}^{-1}$, respectively.

Pyruvate and lactate in the culture supernatant were measured by ion chromatography (IC) (Metrosep A SUPP $5250,4 \times 250 \mathrm{~mm}$ ). A flow of $0.7 \mathrm{~mL} \mathrm{~min}^{-1}$ of eluent containing $1 \mathrm{mM} \mathrm{NaHCO}$ was used. Both acids were detected using a conductivity detector. A volume of $20 \mu \mathrm{L}$ of sample diluted with water to a range of 50 to $250 \mathrm{ppm}$ was injected and analyzed by IC system. Pure pyruvate and lactate were used to generate standard curves.

\section{Calculation of conversion rate}

Consumed Na-4HB was determined by the difference between the Na-4HB amount supplied at the beginning of a cultivation and $\mathrm{Na}-4 \mathrm{HB}$ content left over in the medium after the cultivation. The concentration of $\mathrm{P} 4 \mathrm{HB}\left(\mathrm{g} \mathrm{L}^{-1}\right)$ was determined from cell dry weight $(\mathrm{CDW})$ in $\mathrm{g} \mathrm{L}^{-1}$ and the cellular content of $\mathrm{P} 4 \mathrm{HB}\left(\mathrm{w} \mathrm{w}^{-1}\right)$ obtained at the end the cultivation. The conversion rate was calculated by dividing the mass of carbon in gram from $\mathrm{P} 4 \mathrm{HB}$ with the mass of carbon in gram from $\mathrm{Na}-4 \mathrm{HB}\left(\mathrm{w} \mathrm{w}^{-1}\right)$.

\section{Competing interests}

The authors declare that they have no competing interest.

\section{Authors' contributions}

SLM designed and performed the experiments, prepared and revised the manuscript. MZ and TE participated in designing the experiment and in revising the final manuscript. LTM revised the final manuscript. QR designed and supervised the experiments, prepared and revised the manuscript. All authors read and approved the final manuscript.

\section{Acknowledgement}

We thank Karl Kehl for IC measurements and Melisa Novelli for technical assistances. We thank Prof. Guoqiang Chen (Tsinghua University) for kindly providing the plasmid pKSSE5.3. 


\section{Author details}

${ }^{1}$ Laboratory for Biomaterials, Swiss Federal Laboratories for Materials Science and Technology (Empa), Lerchenfeldstrasse 5, CH-9014, St. Gallen, Switzerland. ${ }^{2}$ Swiss Federal Institute of Technology Zurich (ETH), Environmental Sciences, Rämistrasse 101, 8092, Zurich, Switzerland. ${ }^{3}$ Biotechnology, HES-SO Valais Wallis, Rue du Rawyl 64, P.O.B. 2134, CH-1950 Sion, Switzerland. ${ }^{4}$ Environmental Microbiology, Swiss Federal Institute of Aquatic Science and Technology (Eawag), Überlandstrasse 133, P.O. Box 610, $\mathrm{CH}-8600$, Dübendorf, Switzerland.

Received: 30 October 2013 Accepted: 2 December 2013 Published: 11 December 2013

\section{References}

1. Steinbüchel A, Valentin HE: Diversity of bacterial polyhydroxyalkanoic acids. FEMS Microbiol Lett 1995, 128:219-228.

2. Gogolewski S, Jovanovic M, Perren SM, Dillon JG, Hughes MK: Tissue response and in vivo degradation of selected polyhydroxyacids: polylactides (PLA), poly(3-hydroxybutyrate) (PHB), and poly(3-hydroxybutyrate-co-3hydroxyvalerate) (PHB/PHV). J Biomed Mater Res 1993, 27:1135-1148.

3. Brandl H, Bachofen R, Mayer J, Wintermantel E: Degradation and applications of polyhydroxyalkanoates. Can J Microbiol 1995, 41:143-153.

4. Rathbone S, Furrer P, Lubben J, Zinn M, Cartmell S: Biocompatibility of polyhydroxyalkanoate as a potential material for ligament and tendon scaffold material. J Biomed Mater Res 2010, 93A:1391-1403.

5. Martin DP, Williams SF: Medical applications of poly-4-hydroxybutyrate: a strong flexible absorbable biomaterial. Biochem Eng J 2003, 16:97-105.

6. Engelberg I, Kohn J: Physico-mechanical properties of degradable polymers used in medical applications: A comparative study. Biomaterials 1991, 12:292-304

7. Nelson T, Kaufman E, Kline J, Sokoloff L. The extraneural distribution of Y-hydroxybutyrate. J Neurochem 1981, 37:1345-1348.

8. Choi J, Lee SY: Process analysis and economic evaluation for poly(3-hydroxybutyrate) production by fermentation. Bioprocess Eng 1997, 17:335-342.

9. Xu F, Sun JX, Liu CF, Sun RC: Comparative study of alkali- and acidic organic solvent-soluble hemicellulosic polysaccharides from sugarcane bagasse. Carbohyd Res 2006, 341:253-261.

10. Sun Y, Cheng JY: Hydrolysis of lignocellulosic materials for ethanol production: a review. Bioresour Technol 2002, 83:1-11.

11. Song S, Park C: Utilization of D-ribose through D-xylose transporter. FEMS Microbiol Lett 1998, 163(2):255-261.

12. Kim JS, Lee BH, Kim BS: Production of poly(3-hydroxybutyrate-co-4hydroxybutyrate) by Ralstonia eutropha. Biochem Eng J 2005, 23(2):169-174

13. Saito Y, Nakamura S, Hiramitsu M, Doi Y: Microbial synthesis and properties of poly(3-hydroxybutyrate-co-4-hydroxybutyrate). Polym Int 1996, 39(3):169-174

14. Choi Jl, Lee SY: High-level production of poly(3-hydroxybutyrate-co-3hydroxyvalerate) by fed-batch culture of recombinant Escherichia coli. Appl Environ Microb 1999, 65(10):4363-4368.

15. Sudesh K, Fukui T, Taguchi K, Iwata T, Doi Y: Improved production of poly (4-hydroxybutyrate) by Comamonas acidovorans and its freeze-fracture morphology. Int J Biol Macromol 1999, 25(1-3):79-85.

16. Hein S, Söhling B, Gottschalk G, Steinbüchel A: Biosynthesis of poly(4-hydroxybutyric acid) by recombinant strains of Escherichia coli. FEMS Microbiol Lett 1997, 153:411-418.

17. Zhou X-Y, Yuan X-X, Shi Z-Y, Meng D-C, Jiang W-J, Wu L-P, Chen J-C, Chen G-Q: Hyperproduction of poly(4-hydroxybutyrate) from glucose by recombinant Escherichia coli. Microb Cell Fact 2012, 11(1):54.

18. Luli GW, Strohl WR: Comparison of growth, acetate production, and acetate inhibition of Escherichia coli strains in batch and fed-batch fermentations. App/ Environ Microb 1990, 56(4):1004-1011.

19. Murata T, Horinouchi S, Beppu T: Production of poly(l-aspartyl-Iphenylalanine) in Escherichia coli. J Biotechnol 1993, 28(2-3):301-312.

20. Song S, Hein S, Steinbüchel A: Production of poly(4-hydroxybutyric acid) by fed-batch cultures of recombinant strains of Escherichia coli. Biotechnol Lett 1999, 21(3):193-197.

21. Chang DE, Shin S, Rhee JS, Pan JG: Acetate metabolism in a pta mutant of Escherichia coli W3110: Importance of maintaining acetyl coenzyme a flux for growth and survival. J Bacteriol 1999, 181(21):6656-6663.
22. Wang FL, Lee SY: High cell density culture of metabolically engineered Escherichia coli for the production of poly(3-hydroxybutyrate) in a defined medium. Biotechnol Bioeng 1998, 58(2-3):325-328.

23. Lee SY, Chang HN: Production of poly(3-hydroxybutyric acid) by recombinant Escherichia coli strains: genetic and fermentation studies. Can J Microbiol 1995, 41(13):207-215.

24. Zhang L, Shi Z-Y, Wu Q, Chen G-Q: Microbial production of 4-hydroxybutyrate, poly-4-hydroxybutyrate, and poly(3-hydroxybutyrate-co-4-hydroxybutyrate) by recombinant microorganisms. Appl Microbiol Biotechnol 2009, 84(5):909-916.

25. Li ZJ, Cai L, Wu Q, Chen GQ: Overexpression of NAD kinase in recombinant Escherichia coli harboring the phbCAB operon improves poly(3-hydroxybutyrate) production. Appl Microbiol Biotechnol 2009, 83(5):939-947.

26. Riesenberg D: High cell-density cultivation of Escherichia coli. Curr Opin Biotech 1991, 2(3):380-384

27. Hanahan D: Studies on transformation of Escherichia coli with plasmids. J Mol Bio 1983, 166(4):557-580.

28. YanischPerron C, Vieira J, Messing J: Improved M13 phage cloning vectors and host strains: nucleotide sequences of the M13mp18 and Puc19 vectors. Gene 1985, 33(1):103-119.

29. Bullock W, Fernandez J, Short J: XL1-blue: high efficiency plasmid transforming recA Escherichia coli strain with beta-galactosidase selection. Biotechniques 1987, 5:376-378.

30. Simon $R$, Priefer $U$, Puhler A: A broad host range mobilization system for invivo genetic engineering: transposon mutagenesis in gram-negative bacteria. Biotechnol 1983, 1(9):784-791.

31. Bachmann BJ: Derivations and genotypes of some mutant derivatives of Escherichia coli K-12. In Escherichia coli and Salmonella typhimurium: Cellular and Molecular Biology. Edited by Neidhardt FC. Washington, DC: ASM Press; 1996:2460-2488.

32. Daegelen P, Studier FW, Lenski RE, Cure S, Kim JF: Tracing ancestors and relatives of Escherichia coli B, and the derivation of B strains REL606 and BL21(DE3). J Mol Bio 2009, 394(4):634-643.

33. Marvel CS, Birkhimer ER: The preparation of the sodium salts of omegahydroxybutyric,-valeric and-caproic acids. J Amer Chem Soc 1929. 51(1):260-262

34. Ren Q, Grubelnik A, Hoerler M, Ruth K, Hartmann R, Felber H, Zinn M: Bacterial poly(hydroxyalkanoates) as a source of chiral hydroxyalkanoic acids. Biomacromolecules 2005, 6(4):2290-2298.

35. Lageveen RG, Huisman GW, Preusting H, Ketelaar P, Eggink G, Witholt B: Formation of polyesters by Pseudomonas oleovorans: effect of substrates on formation and composition of poly-(R)-3-hydroxyalkanoates and poly-(R)-3-hydroxyalkenoates. App/ Environ Microb 1988, 54(12):2924-2932.

36. le Meur S, Zinn M, Egli T, Thöny-Meyer L, Ren Q: Production of mediumchain-length polyhydroxyalkanoates by sequential feeding of xylose and octanoic acid in engineered Pseudomonas putida KT2440. BMC Biotechnol 2012, 12(1):53.

37. Braunegg $G$, Sonnleitner B, Lafferty R: A rapid gas chromatographic method for the determination of poly-3-hydroxybutyric acid in microbial biomass. Eur J Appl Microbiol Biotechnol 1978, 6:29-37.

doi:10.1186/1475-2859-12-123

Cite this article as: Le Meur et al:: Poly(4-hydroxybutyrate) (P4HB) production in recombinant Escherichia coli: P4HB synthesis is uncoupled with cell growth. Microbial Cell Factories 2013 12:123.

\section{Submit your next manuscript to BioMed Central and take full advantage of:}

- Convenient online submission

- Thorough peer review

- No space constraints or color figure charges

- Immediate publication on acceptance

- Inclusion in PubMed, CAS, Scopus and Google Scholar

- Research which is freely available for redistribution 